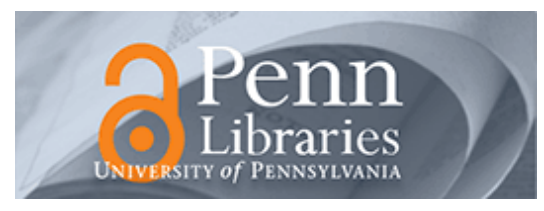

University of Pennsylvania

ScholarlyCommons

Marketing Papers

Wharton Faculty Research

$2-2010$

\title{
Pleasurable Surprises: A Cross-Cultural Study of Consumer Responses to Unexpected Incentives
}

Ana Valenzuela

Barbara Mellers

University of Pennsylvania

Judi Strebel

Follow this and additional works at: https://repository.upenn.edu/marketing_papers

Part of the Cognition and Perception Commons, Cognitive Psychology Commons, Comparative Psychology Commons, Marketing Commons, Multicultural Psychology Commons, Other Economics Commons, and the Social Psychology Commons

\section{Recommended Citation}

Valenzuela, A., Mellers, B., \& Strebel, J. (2010). Pleasurable Surprises: A Cross-Cultural Study of Consumer Responses to Unexpected Incentives. Journal of Consumer Research, 36 (5), 792-805. http://dx.doi.org/ $10.1086 / 605592$

This paper is posted at ScholarlyCommons. https://repository.upenn.edu/marketing_papers/305

For more information, please contact repository@pobox.upenn.edu. 


\title{
Pleasurable Surprises: A Cross-Cultural Study of Consumer Responses to Unexpected Incentives
}

\author{
Abstract \\ Consumer reactions to a surprising event are generally stronger than those to an identical but unexpected \\ event. But the experience of surprise differs across cultures. In this article, we examine differences \\ between East Asian and Western emotional reactions to unexpected incentives. When given an \\ unexpected gift, East Asians report less surprise and less pleasure than Westerners. East Asians' \\ dampened pleasure is explained by their motivation to maintain balance and emotional control, which \\ leads to a reappraisal of perceived likelihood. However, if the unexpected gift is attributed to good luck, \\ which is a desirable form of the unexpected, East Asians experience even greater pleasure than \\ Westerners.

\section{Keywords} \\ affect/emotions/mood, cross-cultural research, motivation/desires/goals, cognitive processes, \\ experimental design and analysis (ANOVA)

\section{Disciplines} \\ Business | Cognition and Perception | Cognitive Psychology | Comparative Psychology | Marketing | \\ Multicultural Psychology | Other Economics | Social Psychology
}


Pleasurable Surprises: A Cross-Cultural Study of Consumer Responses to

Unexpected Incentives

ANA VALENZUELA,

BARBARA MELLERS,

JUDI STREBEL* 


\section{Author Note}

Ana Valenzuela is Assistant Professor at the Zicklin School of Business, Baruch College, New York, NY 10010, e-mail: ana.valenzuela@baruch.cuny.edu. Barbara Mellers is Milton W. Terrill Professor of Business Administration at the Haas School of Business, University of California, Berkeley, Berkeley, CA 94720, e-mail:

mellers@haas.berkeley.edu. Judi Strebel is Associate Professor at the College of Business, San Francisco State University, San Francisco, CA 94132, e-mail: strebel@sfsu.edu. Jeff Gagnon, Chrissy Mitakakis, Rania Semaan, Beth Antonuk and Michele Chung assisted in conducting the experiments. The authors would like to thank the three anonymous reviewers, associate editor and editor, for their comments, and Barry Friedman for his remarks on an earlier draft. The comments of participants at the SCP (Feb 2005) and ACR conference (Oct 2007) are gratefully acknowledged. 
Reactions to a surprising event are generally stronger than reactions to an event that is identical in content, but expected. However, consumers across cultures may not react the same way to the unexpected. In this article, we examine differences between East Asian and Western emotional reactions to unexpected incentives. When given an unexpected gift, East Asians report less surprise and less pleasure than Westerners. East Asians' dampened pleasure is explained by their motivation to maintain balance and emotional control, which leads to a reappraisal of perceived likelihood. However, if the unexpected gift is attributed to good luck, which is a desirable form of the unexpected, East Asians experience even greater pleasure than Westerners. 
In some industries, manufacturers and retailers offer customers token gifts as appreciation for their patronage. Examples include a make-up bag with the purchase of cosmetics or a T-shirt for opening a bank account. Consumers are generally pleased by these incentives, and their pleasure typically corresponds to the extent in which the gifts come as a surprise. Even a small but unexpected gift can have powerful effects. The American Salesman (1996), an industry guide for sales professionals, states that giving a surprising incentive has "an almost magical effect on the winning agent" (26).

Surprise is the astonishment, wonder, or amazement that grows with the unexpectedness and importance of an event. Some psychologists treat surprise as a cognitive process that involves beliefs about the likelihood of an event (Fiske 2002; Teigen and Keren 2003). Others view surprise as an emotion, on par with happiness, sadness, anger, disgust, and fear, because of its unique pattern of facial expressions (Ekman, Friesen and Ellsworth 1972). If surprise is an emotion, it is an unusual one, since it can be either pleasant or painful. The role of surprise is one of emotional amplification (Kahneman and Miller 1986; Elster 1998). Unexpected gains bring more pleasure than expected gains, and unexpected losses cause more pain than those that are expected (Mellers, Schwartz, Ho and Ritov 1997; Mellers, Schwartz and Ritov 1999). This hedonic amplification has been demonstrated across both domains (Mellers and McGraw 2001; Filipowicz 2006) and species (Schultz and Dayan 1997). It is also associated with the so-called "pleasure paradox" (Wilson, Centerbar, Kermer and Gilbert 2005): People want their worlds to be predictable, although unpredictable outcomes are more exciting.

To explain the effects of surprise on pleasure, Mellers et al. $(1997,1999)$ developed an account of judged emotions called decision affect theory. Surprise enhances emotional 
experiences, sometimes even making objectively better outcomes less pleasurable than an unexpected, worse one. Mellers et al. (1997) found that a surprising \$9 win is more enjoyable than an expected $\$ 17$ win. Likewise, a surprising \$9 loss is more painful than an expected \$17 loss.

Previous research has also demonstrated the beneficial effects of surprise on consumer choice. Unexpected in-store coupons increase the overall number and dollar value of unplanned purchases, whether utilitarian or hedonic (Heilman et al., 2002). Unexpected advertising claims produce greater message involvement and more favorable evaluations of the ad (Lee 2000). Finally, unexpected results, combined with delight, pleasure, joy, or elation increases both customer loyalty (Oliver, Rust and Varki 1997) and positive word-ofmouth (Berman 2005).

Although unexpected marketing incentives can have powerful effects on consumer behavior, not all consumers react to them in the same way.. This article, investigates cross-cultural differences between East Asians and Westerners in their emotional reactions to unexpected incentives. Cross-cultural differences in how surprise is experienced are likely to arise from two different processes. First, Westerners and East Asians differ in their modes of thought (Choi and Nisbett 2000), and these different modes influence perceived connections, causal linkages, and beliefs about events, as well as hindsight after the event. Second, Westerners and East Asians differ in their feelings about and desires from the unexpected. For Westerners, an unforeseen gift may be viewed as a sign of an intrinsic recognition of self-worth. For East Asians, an unexpected gift might be a harbinger of misfortune (Uchida, Noasakkunkit and Kitayama 2004). East Asians are more motivated than Westerners to achieve balance and harmony in their 
lives. Faced with the unexpected, East Asians tend to reappraise past assumptions rather than delight in surprise.

These forces in play, we expect East Asians (compared to Westerners) to form post hoc estimates that downplay the unexpectedness of an event. We also expect East Asians to experience less surprise than Westerners from unanticipated incentives. And, less surprise leads to less pleasure. However, an unpredicted prize attributed to good luck may reverse this pattern. While an East Asian's inclination toward emotional control might protect him from "man-made" (i.e., real-world, tangible, effort-based) influences, this tendency might subside when fate or chance are involved (Li 2006). Since East Asians believe in destiny control (Young et al. 2005), they may view good luck as a welcomed indication of a positive and harmonious outlook. Luck-based, unexpected positive outcomes may amplify an East Asian's positive emotions more than they would a Westerner's. We test these propositions by examining emotional reactions to expected (announced) and unexpected (unannounced) gifts, judgments of surprise, and post hoc estimates of likely response.

\section{CULTURAL DIFFERENCES IN THE EXPERIENCE OF SURPRISE}

Past research on cross-cultural differences characterizes East Asians as holistic reasoners and Westerners as analytic reasoners (Nisbett, Peng, Choi, and Norenzayan 2001). The holistic reasoning style of Asian cultures is guided by the assumption that everything in the universe is connected (Norenzayan, Choi and Nisbett 1999). Chinese children use a more relational approach to object grouping than American children (Chiu 
1971). Relative to Westerners, East Asians are better at detecting associations among events (Peng and Nisbett 1999). Moreover, East Asians tend to develop more complex theories of the world to accommodate their belief in a high degree of interconnectedness (Choi, Nisbett and Norenzayan 1999).

Because they hold more complex and holistic views of the world, East Asians are less likely to experience surprise, perhaps, than Westerners. Choi and Nisbett (2000) found that East Asians were less surprised by outcomes that directly contradicted expectations (e.g., a generous seminary student who behaved selfishly). Their findings showed that East Asians also exhibited greater hindsight (Fischhoff 1975) than Westerners. That is, East Asians felt that they knew the outcome would occur all along, although it actually contradicted their a priori expectations. When confronted with contradictions, East Asians tend to reconcile opposites, seek a middle way and transcend points of disagreement. This propensity for reevaluation allows previously implausible outcomes to become plausible. In contrast, Westerners are more likely to confront contradictions and reject at once the least plausible proposition (Peng and Nisbett 1999).

In sum, if one believes that the world is explained by multiple factors with complex connections, one is more likely to find post hoc explanations for unforeseen events. East Asians are more inclined to these sorts of explanations than Westerners, even for events that contradict prior beliefs (Choi, Nisbett and Norenzayan 1999).

In this article, we are interested in emotional reactions to unanticipated incentives that do not necessarily run counter to expectations. It is our believe, that the holistic processing style of East Asians facilitate more complex rationalizations for the 
unexpected. Those rationalizations affect East Asian estimations of an event's probability, their experience of surprise, and their pleasure from receiving a surprise gift. Another explanation for cross-cultural differences in surprise involves motivation. East Asian cultures strongly emphasize social harmony (Fiske et al. 1998; Markus and Kitayama 1991b). Keeping balance and harmony amidst extremes has been viewed as one of the highest virtues in Chinese culture since the Yao and Shun era (2357-2205 BC). Harmony was also considered a virtue by Confucius (Uno 1991). Individuals in East Asian societies are taught that the private self should be secondary to the social self (Yang-Soo 1981). In other words, the importance of being connected to others makes East Asians more likely to perceive themselves as ordinary (Markus and Kitayama 1994). In contrast, Westerners are more likely to perceive themselves as unique and special. Therefore they move away from anything that implies conformity (Heine and Lehman 1997). In East Asian cultures, conformity is highly valued. For example, the Korean word for "conformity" means "maturity" and "inner strength."

The motivation to maintain social harmony causes East Asians and Westerners to differ in their experiences of positive events. The Tao-Te Ching (the basis for Taoism), which epitomizes Chinese norms, says: "When positive events occur, one should not be overly happy, but rather acknowledge that things could easily take a turn for the worse." Intense happiness can damage social relations and lead to jealousy and envy (Suh 2002). For East Asians, the experience of happiness comes from the realization of social harmony, not from the separation of self from the rest of society (Kitayama and Markus 2000). In contrast, Westerners are more prone than East Asians to manage their emotions in pursuit of self-regard (Heine at al. 1999). 
In summary, when individuals are motivated to look for signs of personal achievement, favorable events may be interpreted as an affirmation of the self. Westerners might view an unexpected incentive as a signal of individual success and worth. In contrast, when individuals are motivated to seek harmony and balance, favorable events for one may upset a balance with others (e.g. Diener and Suh 2003). For East Asians, unanticipated incentives might indicate hazard to socio-emotional balance. It is logical, therefore, for East Asians to downplay the "unexpectedness" of incentives by assuming they are ordinary occurrences. Relative to Westerners, East Asians may reappraise an incentive and reduce their emotional responses to it (Gross and John 2003). In other words, an East Asians's disposition toward harmony and balance with others affects the nature of their reasoning, leading to an overestimation of an incentive's probability (Kunda 1990).

Even if East Asians are motivated to reduce their exposure to unforeseen events, there may be circumstances in which unexpected incentives are acceptable. Consider the possibility that the unexpected promotional incentive can be attributed to good luck. The Confucian understanding of an orderly world--which prevails in East Asia--differs significantly from other major world traditions (Young et al. 2005). In Christianity, God created the world with a purpose for each and every part of creation. Christians should obey the order and rules ordained by God. The Confucian tradition asserts no order or natural law from God. Rather, it declares that the world must generate its own order Ancient Confucians believed that various parts of the world negotiate with one another. Balance, harmony, or "karma" is achieved through compromise". Whereas Westerners tend to act on and alter the world, East Asians tend to accommodate it (Weisz, Rothbaum 
and Blackburn 1984). If the world negotiates its own order, it can also provide signs of an individual's harmony with the world or good karma. In this context, the experience of luck signals a favorable destiny and a positive outlook on life (Weisz et al. 1984).

In view of these beliefs, East Asians interpretations of an unexpected event can depend on the type of intervening force driving it. If East Asians downplay the "unexpectedness" of an event to avoid upsetting their balance with others, this motivational bias should only be active when "manmade" (i.e., real-world, tangible, effort-based) forces are apparent (Li 2006). This inclination should subside when other, non-manmade forces are involved, such as fate or chance. From this perspective, luck becomes a welcome phenomenon (Heider 1958). A positive event attributed to luck therefore represents no hazard to socio-emotional balance. As a consequence, luckrelated events represent situations in which East Asians may be motivated to respond positively.

We propose that Westerners and East Asians will react differently to an unexpected incentive depending on the intervening force behind it. The intervening force could be a real-world process (a tangible, effort-based power) or luck (an intangible, fate-oriented power). We expect East Asians to be happier than Westerners with unexpected, luckrelated incentives since they are understood as signals of good "karma," universalconnectedness, and positive things to come. In contrast, we expect Westerners to derive more happiness than East Asians when a real-world process leads to an unexpected reward (possibly for one's efforts), offering evidence of their power to alter and control the world. 


\section{THEORETICAL FRAMEWORK}

For both cognitive and motivational reasons, consumers with different culturalorientations may experience surprise differently after receiving an unexpected incentive (see figure 1). First, East Asians' holistic processing style may facilitate the generation of multiple and related reasons behind the unexpected incentive. If East Asians more easily develop causal explanations for the unexpected incentive, they may feel as if the event was easier to anticipate. To them, the unanticipated incentive may be less surprising and, in hindsight, more expected. Thus, we would expect individual differences in the extent of holistic reasoning to influence consumers' experience of surprise.

$\overline{\text { Insert figure } 1 \text { about here }}$

Second, East Asians believe in the need to maintain contextual harmony and balance their positive and negative emotional experiences (Williams and Aaker 2002). When East Asian consumers encounter a surprising incentive, it might indicate imbalance in their social order and, thus, threatening. East Asians may respond to unexpected incentives by reappraising perceived outcomes and suppressing the experience of surprise. In contrast, Westerners may be more likely to view the unexpected incentive as a pleasurable experience that reinforces the value of their skills and control of the environment (Langer 1975). If so, we would expect individual differences in the enjoyment of personal control and confidence in emotional control to determine consumers' experience of surprise. This response would be malleable when priming different control motivations. 
Whether the effect is related to differences in holistic processing or differences in the motivation to stay interconnected, we expect that East Asians will be more likely than Westerners to generate beliefs about unforeseen incentives that downplay their surprise, resulting, therefore, in less pleasure.

H1: Westerners will derive greater momentary pleasure than East Asians from an unanticipated positive incentive. When the incentive is expected, Westerners and East Asians will experience similar affective responses.

Attributions of unexpectedness to good luck will change this pattern. If East Asians downplay the "unexpectedness" of an event to avoid upsetting their balance with others, then, this motivational bias may only be active when "man-made" (i.e., tangible, effortbased) forces are apparent and, thus, subside when fate or chance are involved (Li 2006). The idea is that, since East Asians believe in destiny control, they will perceive a luckrelated event as a positive signal from the environment (Young et al. 2005). If that is the case, East Asians will experience both enhanced surprise and momentary pleasure from an unexpected incentive when it can be attributed to luck instead of effort.

H2: East Asians will derive greater pleasure than Westerners from an unanticipated positive incentive attributed to good luck. When the incentive cannot be easily attributed to luck but rather effort, Westerners will derive greater momentary pleasure than East Asians.

We are not advocating a single mechanism behind these effects. Cultural differences in cognition and motivation are highly intertwined, so either or both cognitive and motivational routes could shape the experience of surprise and hence the experience of pleasure from receiving an unexpected positive incentive. 


\section{OVERVIEW}

We now present four experiments that explore cross-cultural differences in the experience of surprise and pleasure from receiving an unexpected promotional incentive. Experiment 1 investigates whether the momentary feelings of pleasure from an unexpected gift are stronger for Westerners (U.S.) than for East Asians (Chinese, Japanese, and Korean). Westerners feel greater enjoyment than East Asians from receiving an unexpected gift relative to receiving no gift or an expected gift. Experiment 2 examines the cognitive and motivational underpinnings. An unexpected positive event produces less surprise and greater hindsight in East Asians (Taiwanese) than in Westerners (Caucasian Americans). Furthermore, cross-cultural differences in the experience of surprise mediate pleasure. Finally, motivations for personal control and for balancing the environment, but not holistic reasoning, predict the experience of surprise. In Experiment 3, we prime pleasure-seeking motives versus balancing motives to manipulate East Asians experiences of surprise and pleasure. When primed with pleasure-seeking motives, East Asians' pattern of experienced surprise and pleasure is similar to that previously found for Westerners. In Experiment 4, we investigate the effect of unexpected incentives that are attributable to good luck. East Asians more easily adopt an explanation based on their own good fortune, and this tendency predicts their enhanced experience of surprise and pleasure.

Experiment 1: Differences in the Momentary Pleasure of Unexpected Incentives 
The purpose of this study is to compare East Asians' and Westerners' feelings of momentary pleasure after the receipt of an unexpected incentive, a gift. We use two baselines for comparison. Momentary feelings are measured after the receipt of an unexpected gift compared to those who received no gift at all, and measured against feelings of those who received an expected gift.

Participants. Participants were undergraduates in a business course at a large West Coast university in the United States (58\% females and 42\% males, mean age 20). Participation was rewarded with course credit. Because of our focus on Western and East Asian cultures, we onlt analyzed the answers of those students who were born in East Asian countries and had lived in the U.S. for fewer than five years, or who were born in the U.S. and identified themselves as Caucasian. Results are based on the answers of 39 East Asians and 34 Westerners in Version 1 (with no gift as the baseline) and 21 East Asians and 19 Westerners in Version 2 (with the expected gift as the baseline).

Stimuli and Procedure. Each version of the experiment had two levels. In version 1, subjects were told at the end of the research session that the University Bookstore wanted them to fill out a customer satisfaction survey. In one condition, subjects received an unexpected gift (university car sticker valued at \$2) as a token of appreciation. In the other condition, subjects received nothing. All subjects were asked, "How pleased/ excited/ happy are you currently feeling?" on a one to seven category rating scale (where $1=$ "Not at all", $7=$ "A lot"). 
In a second version of the study, all subjects received a gift of a \$2 gift certificate redeemable at the University Café. The gift was described as a token of appreciation for their participation. Ratings of the desirability of the gifts did not vary significantly across countries $(M=4$ for Asians vs. 3.5 for Americans, $\mathrm{F}(1,37)=1.01, p>.30)$. In one condition, the experimenter announced at the beginning of the experiment that everyone would receive gift certificates, so the incentives were expected. In the other condition, no prior announcement was made, so the gift certificates were unexpected. After receiving gift certificates, subjects indicated how pleased, excited, and happy they felt.

Momentary Pleasure. We constructed a composite variable of reported pleasure based on measures of excited, happy, and pleased (alpha $=.91)$. There was a significant main effect of the gift; participants receiving the unexpected gift were momentarily happier than those who received nothing $\left(F(1,73)=39.18, p<.001, \eta^{2}=.33\right)$. Receiving a gift increased pleasure for East Asians $\left(F(1,38)=7.09, p<.05, \eta^{2}=.16\right)$ and Westerners $\left(F(1,34)=41.05, p<.01, \eta^{2}=.55\right)$. We also identified a significant interaction between gift and culture on momentary pleasure $\left(F(1,73)=5.66, p<.05, \eta^{2}\right.$ $=.08$ ). This interaction is shown on the left side of Figure 2, with pleasure shown against gift (yes/no), with separate curves for Westerners and East Asians. When Westerners and East Asians received nothing, they did not differ in their momentary pleasure $(M=3.5 \mathrm{vs}$. $3.9 ; F(1,35)=2.46, p>.15)$. When both groups received an unexpected gift, Westerners reported significantly greater pleasure $\left(M=5.7\right.$ vs. $\left.5.0 ; F(1,37)=3.29 p<.05, \eta^{2}=.09\right)$.

To compare momentary feelings associated with expected and unexpected gifts, we constructed the same composite variable $(\mathrm{alpha}=0.88)$ and found a significant 
interaction between beliefs about gifts (expected vs. unexpected) and culture $(F(1,39)=$ $\left.11.18, p<0.01, \eta^{2}=.24\right)$ on pleasure. This interaction is shown on the right of figure 2 . When the \$2 gift certificate was expected, Westerners and East Asians did not differ in their momentary feelings $(M=4.3$ vs. $4.4 ; \mathrm{F}(1,20)=.02, p>.80)$. When the gift was unexpected, Westerners were significantly more pleased than East Asians ( $M=6.3$ vs. $\left.5.0 ; F(1,18)=6.97, p<.01, \eta^{2}=.39\right)$. Cultural comparisons showed that unexpectedness increased the immediate pleasure of Westerners $\left(F(1,14)=23.84, p<.01, \eta^{2}=.65\right)$ but not of East Asians $(\mathrm{F}(1,24)=1.06, p>.30)$.

\section{Insert figure 2 about here}

Discussion. As predicted Westerners feel greater enjoyment than East Asians after an unexpected gift relative to no gift at all, and relative to an expected gift. In addition, our finding that there was no significant difference in feeling between Westerners and East Asians when it comes to no gift versus expected gift, supports the argument against a cultural bias to gift reception, per se. Next, we examine the cognitive and motivational underpinnings behind the differences in reports of momentary pleasure.

\section{Experiment 2: Pleasure, Surprise and Hindsight}

This experiment examines the roles of experienced surprise and judged hindsight on reported momentary pleasure using a sample collected from East Asian (Taiwan) and Western (U.S.) universities. We also investigate whether cross-cultural differences in 
reasoning tendencies (holistic v. cognitive) and the motivation toward controlling or balancing one's environment predict the experience of surprise.

Participants. Participants were 70 ethnically Chinese students from a Taiwanese (Taipei) university and 102 ethnically Caucasian students at a U.S. (West Coast) university ( $52 \%$ females and $48 \%$ males, mean age 26$)$. All of them received course credit for their participation.

Stimuli and Procedure. Experimenters announced at the beginning of a lecture that students would have the opportunity to participate in a study beginning 10 minutes after class. In exchange, they would receive extra course credit. In one condition, the experimenter announced from the beginning, that participants would receive a gift (incentive) as appreciation for their participation, in addition to course credit. In the other condition, promises of a gift were not made until just before the survey. After choosing their gift (a bag of potato chips, a coffee drink or a three-unit pack of chewing gum, all of them desirable in both cultures: 4.6 for East Asians and 4.3 for Westerners on average; F $(1,158)=1.25, p>.20)$, respondents were asked "How pleased (excited, happy) are you currently feeling?" on a one to seven category rating scale (where $1=$ "Not at all" and $7=$ "A lot"). They were also asked about negative affect: "How frustrated are you currently feeling?" on the same scale. Finally, they had to report an overall evaluation of their emotional state: "Overall, how do you feel?" on a minus three to three category rating scale $($ where $-3=\mathrm{Bad}$ and $3=\mathrm{Good})$. 
To measure surprise, experimenters asked participants, "How surprised were you to have received the gift as a token of appreciation?" Ratings were made on a one to seven scale (This question was similar to that used by Choi and Nisbett 2000). To measure hindsight, we used two scales: First, participants were asked to judge, on a scale of zero to 100 , what they thought was the probability of receiving a gift as a token of appreciation prior to learning they would actually receive one. Second, participants judged the extent to which they had expected a gift on a one to seven scale. These questions have been used in the past to measure hindsight (e.g., Fischhoff 1975).

Next, participants were asked to respond to questions from the Affect Intensity Scale (Larsen, Diener and Emmons 1985), rating their emotional reactions on a one to six scale. Then, on a one to seven scale, participants stated the extent to which they agreed with statements from the Casual Reasoning section of Choi, Koo and Choi's AnalysisHolism Scale (2007), the Emotional Self-Control section of Kim's Asian Values Scale (1999), and Burger and Cooper's Desirability of Control Scale (1979). Some examples of items in each of the scales are: i) Analysis-Holism: "Everything in the world is intertwined in a causal relationship," "Any phenomenon has numerous causes, although some of the causes are not known," ii) Emotional Self-Control: "The ability to control one's emotions is a sign of strength," "One should have sufficient inner resources to resolve emotional problems," iii) Desirability of Control: "I enjoy making my own decisions," "I enjoy having control over my own destiny."

Momentary Pleasure. To compare momentary feelings after an expected (announced) and unexpected (unannounced) gift, we constructed the same composite variable (pleased/excited/happy; alpha $=0.95$ ) and found a significant differences on 
perceptions of pleasure based on the interaction (see figure 3a) between beliefs about the incentive's occurrence (expected vs. unexpected) and culture $(F(1,171)=4.31, p<0.04$, $\left.\eta^{2}=.02\right)$. When the incentive was expected, Westerners and East Asians did not differ in their momentary feelings $(M=4.2$ vs. $4.5 ; \mathrm{F}(1,110)=1.01, p>.80)$. But when the incentive was unexpected, Westerners were significantly more pleased than East Asians $\left(M=5.0\right.$ vs. $\left.4.4 ; F(1,60)=4.77, p<.05, \eta^{2}=.07\right)$. Intra-culture comparisons showed that unexpectedness increased the immediate pleasure of Westerners $(F(1,101)=11.18$ $\left.p<.01, \eta^{2}=.09\right)$ but not of East Asians $(\mathrm{F}(1,69)=.004, p>.90)$.

Analysis of participant overall evaluations of their emotional state replicates these results. We found significant effect on overall emotional evaluations from the interaction between beliefs about the incentive's occurrence (expected vs. unexpected) and culture $\left(F(1,170)=19.35, p<0.01, \eta^{2}=.11\right)$. When the incentive was expected, Westerners felt worse than East Asians $\left(M=1.3\right.$ vs. $\left.2.3 ; \mathrm{F}(1,109)=10.08, p<.01, \eta^{2}=.09\right)$. However, when the gift was unexpected, Westerners felt significantly better than East Asians $(M=$ 2.1 vs. $\left.1.1 ; F(1,60)=18.30, p<.01, \eta^{2}=.24\right)$. Within-culture comparisons showed that unexpectedness made Westerners feel better $\left(F(1,101)=10.53, p<.01, \eta^{2}=.09\right)$ and East Asians feel worse $\left(\mathrm{F}(1,68)=7.57, p<.01, \eta^{2}=.12\right)$.

\section{Insert figure 3 about here}

This pattern of results reverses when reporting negative-balanced emotions (negative affect). We again found a significant interaction in ratings of momentary "frustration" $\left(\mathrm{F}(1,170)=6.55, \mathrm{p}<0.01, \eta^{2}=.04\right)$. Intra-culture comparisons showed that unexpectedness made Westerners feel less frustrated $(\mathrm{M}=1.8$ vs. 2.8; $\mathrm{F}(1,112)=8.74$, 
$\left.\mathrm{p}<.01, \eta^{2}=.08\right)$ but did not change East Asians' level of frustration (M=2.5 vs. 2.2; F (1, $57)=.87, \mathrm{p}>.30)$.

Surprise. Figure $3 b$ shows judged surprise plotted against beliefs with separate curves for each culture. We found a significant interaction between beliefs about the incentive's occurrence (expected vs. unexpected) and culture $(F(1,171)=5.90, p<0.05$, $\eta^{2}=.03$ ) on judged surprise. When the gift was announced beforehand, East Asians and Westerners expressed roughly equivalent surprise $(M=4.2$ vs. $3.6 ; F(1,109)=2.26$, $p>.15, \eta^{2}=.02$ ). However, when the gift was unexpected, Westerners reported significantly more surprise than East Asians. Mean ratings of surprise are 5.2 and 4.5 for Westerners and East Asians, respectively $\left(F(1,60)=4.24, p<.05, \eta^{2}=.07\right)$.

We propose that differences in judged surprise mediate the moderating effect of culture on the increase in immediate pleasure that occurs from the unexpected nature of the incentive. Mediated moderation occurs when a mediator (Me: judged surprise) of a treatment effect (X: beliefs about the incentive's occurrence) on a variable (Y: reported pleasure) depends on the moderator (Mo: culture). According to Muller, Judd and Yzerbyt (2005), two conditions must hold for mediated moderation: First, there must be an overall moderation of the treatment effect $\left(b_{13} \neq 0\right.$ and $b_{33}$ is smaller in absolute value than $\left.b_{13}\right)$. Second, the mediator must account for the moderation. To establish this link, the effect of $X$ on Me has to depend on $M o\left(b_{23} \neq 0\right.$ and $\left.b_{34} \neq 0\right)$. This analysis requires three regressions (see table 1 for estimated coefficients and associated t-statistics).

Insert table 1 about here 
We find evidence for the predicted interaction between beliefs about the incentive's occurrence (X) and culture (Mo). The effect of an unannounced gift on pleasure is moderated by culture $\left(\mathrm{b}_{13}=-.202\right)$. Westerners, but not East Asians, derive significantly greater pleasure from an unannounced gift than an announced gift. Second, there is a significant interaction between beliefs about the incentive occurrence $(\mathrm{X})$ and culture (Mo) on judged surprise $\left(b_{23}=-.340\right)$, and a significant effect of surprise on pleasure $\left(b_{34}\right.$ $=.461)$. In other words, momentary pleasure depends on judged surprise, which varies with beliefs about the incentive's occurrence and culture. Finally, the interaction between culture and gift announcement is smaller after controlling for surprise $(|-.049|<|-.202|)$. We also calculated the Sobel's test of the mediation pattern, which results in a value of $2.40, p<.01$. Thus, judged surprise mediates the effects of culture and beliefs in the incentive's occurrence on momentary pleasure.

Hindsight. Figure $3 \mathrm{c}$ shows judged hindsight (the estimated probability of receiving an incentive after receipt of the incentive) plotted against the belief of the incentive's occurrence with separate curves for each culture. This interaction was marginally significant $\left(F(1,167)=2.76, p<.10, \eta^{2}=.02\right)$. When the gift was expected, East Asians and Westerners did not differ in their hindsight. Mean probabilities were $58 \%$ and $50 \%$ for East Asians and Westerners. But when the gift was unexpected, East Asians reported more hindsight than Westerners. Mean probabilities were $62 \%$ and 38\% for East Asians and Westerners, respectively $\left(F(1,60)=10.81, p<.01, \eta^{2}=.16\right)$.

Similar results are obtained with a different measurement of hindsight (extent to which one had expected the incentive). The interaction of culture and beliefs about the 
incentive's occurrence on hindsight is also statistically significant $(F(1,167)=4.56, p<$ $\left..05, \eta^{2}=.03\right)$. When the gift was expected, East Asians and Westerners did not differ in their hindsight expectations $(M=4.3$ vs. 3.8$)$. But when the gift was unexpected, East Asians report more hindsight than Westerners $(M=4.8$ vs. $2.9 ; F(1,60)=15.23, p<$ $\left..01, \eta^{2}=.21\right)$. Finally, hindsight and surprise were correlated. Greater hindsight went hand-in-hand with less surprise $(r=-0.18, \mathrm{p}<.05)$.

\section{Cultural Differences in Affect Intensity, Holism, Desirability of Control and}

Confidence in Emotional Control. To examine the possibility that cross-cultural differences in pleasure could be due to a general tendency by Westerners to respond more extremely to positive outcomes, we analyzed results of the Affect Intensity Scale (Larsen et al. 1985). There were no cultural differences in affect intensity (3.6 East Asians vs. 3.7 Westerners; $F(1,130)=1.62, p>.20)$. To explore cross-cultural differences in holistic thinking, we used Choi et al.'s (2007) Analysis-Holism scale. East Asians were more likely than Westerners to reason holistically $(M=5.6$ vs. $5.0 ; F(1,170)=23.75, p<.01$, $\eta^{2}=.12$ ). To explore differences in personal control, we used the scales developed by Burger and Cooper (1979) and Kim (1999). Westerners were more likely than East Asians to enjoy personal control over their destiny $(M=5.4$ vs. $5.0 ; F(1,170)=3.83, p$ $\left.<.01, \eta^{2}=.06\right)$; while East Asians were more likely to place importance on their ability to control their emotions $\left(M=4.9\right.$ vs. $\left.4.2 ; F(1,170)=10.01, p<.01, \eta^{2}=.06\right)$. In other words, we find both cognitive and motivational differences by cultural orientation.

In the case of East Asians, both the enjoyment of personal control and the confidence in emotional control were significantly correlated with the reported surprise from an 
unexpected incentive. Greater experience of surprise was connected with more enjoyment of personal control $(\mathrm{r}=0.52, \mathrm{p}<.01)$ and more confidence in emotional control $(\mathrm{r}=0.43$, $\mathrm{p}<.05)$. A positive correlation between Kim's (1999) emotional control subscale and the experience of surprise in the case of East Asians denotes enhanced confidence or perceived ability to stay in control, thus, enabling individuals to feel surprise without jeopardizing their need for balance. None of these variables were significant predictors of judged surprise for Westerners. Holistic casual reasoning was also not a predictor of judged surprise for either Westerners or for East Asians $\left(p_{s}>.10\right)$.

To explore further the influence of these three traits variables, ANOVAs on momentary pleasure, judged surprise and hindsight were run including these as covariates. Overall, the interaction between beliefs about the incentive's occurrence and culture remained significant for surprise $\left(F(1,168)=7.61, p<.01, \eta^{2}=.05\right)$ but turned marginally significant for pleasure $\left(F(1,170)=2.87, p<.10, \eta^{2}=.02\right)$ and hindsight $(F$ $\left.(1,170)=2.43, p<.10, \eta^{2}=.02\right)$. Although none of the covariates was significant at the overall level, when the same ANOVAs were run by cultural orientation, desirability of control became a significant covariate of judged surprise for Westerners $(F(1,109)=$ $\left.4.59, p<.05, \eta^{2}=.04\right)$, and a marginally significant covariate of momentary pleasure for East Asians $\left(F(1,58)=3.66, p<.06, \eta^{2}=.06\right)$. Additionally, holistic reasoning was a significant covariate with the extent of hindsight bias for both East Asians $(F(1,58)=$ $\left.3.66, p<.06, \eta^{2}=.06\right)$ and Westerners $\left(F(1,58)=5.70, p<.01, \eta^{2}=.05\right)$, and confidence in emotional control with the extent of hindsight bias for East Asians only ( $F$ $\left.(1,58)=19.07, p<.01, \eta^{2}=.27\right)$. 
Discussion. Experiment 2 replicated experiment 1's results with data collected in both East Asian and Western universities. Once again, culture moderated the effect of beliefs about the incentive's occurrence on reported pleasure. Furthermore, cross-cultural differences in momentary pleasure were mediated by experienced surprise, which, in turn, was correlated with judged hindsight. Westerners exhibited more surprise, less hindsight, and greater momentary pleasure from an unexpected gift.

In the framework depicted in figure 1, we proposed that these cross-cultural differences could be attributed to two processes. The first process is based on cultural differences in thinking styles. The second process is based on differences in control motivations. In this study, results supported that, for East Asians, the experience of surprise seems to be connected to a motivational process, which, in turn, drives the cognitive reappraisal of probability beliefs. Next, we explore whether either reducing East Asians' motivation to stay in control (priming pleasure-seeking instead of control: Experiment 3) or enhancing their enjoyment of unexpectedness by attributing it to luck (Experiment 4), could increase their reported pleasure from unexpected incentives.

Experiment 3: Priming Motivation for Control and Balance

This experiment examines the effect of priming emotional control versus pleasure-seeking motivations on East Asians' reported momentary pleasure, the extent of hindsight and the experience of surprise.

Participants. Participants were undergraduates in introductory business courses at large American universities on the East and West Coasts (62\% females and 38\%males, 
mean age $=19$ ). Participation was rewarded with course credit. We only used the responses of those students who were born in East Asian countries and had lived in the U.S. for fewer than five years $(n=42)$.

Stimuli and Procedure. The experiment was conducted during a one-hour marketing research session. In one condition, the experimenters announced at the beginning of the session that participants were going to receive a gift as a token of appreciation for their participation. In the other condition, no such announcement was made until just before the "exit survey". After the initial announcement (if any), participants were asked to write about a situation that had occurred in their life. There were two different priming conditions:

i) "In particular, we would like you to tell us about a time when you were trying to find balance in your life in some important way. This might concern a situation in which you were trying NOT to feel too excited, or too eager, or too worried or too overly enthusiastic about an event."

ii) "In particular, we would like you to tell us about a time when you were trying to enjoy an event to the fullest extent in some important way. This might concern a situation in which you were trying to have a feeling of TRUE happiness, enthusiasm, excitement or joy about an event."

After writing the story, respondents were asked to answer a few questions regarding their personal event. One of those questions served as a manipulation check: "To what extent do these events suggest that it is best to look for a balance in your emotions so as not to feel extremes?" seven-point scale ( $7=$ A lot; $1=$ Not at all). At that 
point, subjects participated in two unrelated studies that served as filler tasks. Then, they were allowed to choose their gift incentive (a bag of potato chips, a chocolate bar or a 3unit pack of chewing gum) and answer what was called an "Exit survey". In that survey, respondents were asked again "How pleased (excited, happy) are you currently feeling?" "How surprised were you to have received the gift as a token of appreciation?" and the two measures of hindsight used in study 2 .

Manipulation Check. As expected, respondents in the "emotional balancing condition" agreed that the event they wrote about suggested that it is best to look for balance in one's emotions ( $M=5.9$ vs. 4.2 in the other condition; $F(1,40)=31.04, p<$ $\left..01, \eta^{2}=.26\right)$.

Momentary Pleasure. We compare momentary feelings (composite variable; alpha $=0.85$ ) after an unexpected incentive to those after an expected incentive for East Asians in both priming conditions. When we prime emotional control, momentary feelings after both expected and unexpected incentives do not differ significantly $(M=$ 3.5 vs. $4.5, F(1,17)=.659, p>.40)$. However, when East Asians are primed with a lack of emotional control (pleasure-seeking), momentary feelings after an unexpected incentive become more positive than those after an expected incentive ( $M=4.9$ vs. $3.2, F$ $\left.(1,23)=2.83, p<.10, \eta^{2}=.24\right)$. This pattern of results is similar to that found for Westerners in our two prior studies. 
Surprise. We identified a marginally significant interaction between beliefs about the incentive's occurrence and priming condition $\left(F(1,41)=2.87, p<.10, \eta^{2}=.11\right)$. When primed with emotional control, East Asians did not show any difference in experienced surprise with expected and unexpected incentives $(M=4.6$ vs. $4.7 ; F(1,17)$ $=.004, p>.90)$. However, when primed with a lack of emotional control, East Asians experienced significantly greater surprise with unexpected than expected incentives $(M=$ 5.2 vs. $\left.2.5 ; F(1,23)=7.36, p<.05, \eta^{2}=.45\right)$. Surprise and reported pleasure were significantly correlated $(\mathrm{r}=0.80, \mathrm{p}<.01)$.

Hindsight. East Asians who were primed with emotional control did not differ in their estimated probability of receiving an incentive (32\% vs. $34 \%$ for the unexpected and expected incentive condition respectively; $F(1,17)=.027, p>.90)$. However, when East Asians were primed with a lack of emotional control, the estimated probability of receiving the incentive was lower when the incentive was unexpected than expected $\left(22 \%\right.$ vs. $\left.35 \% ; F(1,23)=3.30, p<.07, \eta^{2}=.07\right)$.

Similar results occurred with measures of hindsight. Under the emotional control prime, East Asians had similar beliefs that they were going to receive an incentive with expected and unexpected incentives $(M=2.7$ vs. $2.5 ; F(1,17)=.005, p>.90)$. However, when primed with a lack of emotional control, East Asians lowered their beliefs that they were going to receive an incentive when that incentive was unexpected (1.4 vs. $3.2 ; F$ (1, 23) $\left.=4.26, p<.05, \eta^{2}=.20\right)$. 
Discussion. Experiment 3 shows that East Asians, when primed to put less emphasis on emotional control, reveal patterns of momentary pleasure, experienced surprise, and post-hoc beliefs (hindsight) that resemble those exhibited by Westerners in our prior two studies. These findings further demonstrate that cross-cultural differences in affective reactions to unexpected events have a motivational component. The next study examines this explanation by adding the possibility of attributing the gift to luck.

Experiment 4: Attributing Unexpectedness to Good Luck

This study examines whether East Asians exhibit greater pleasure from an unexpected incentive when the incentive can be attributed to good luck. Past research shows that East Asians score higher than Westerners on the "belief in good luck" scale (Hong and Chiu 1988). Results of a pretest (30 Westerners and 37 East Asians) supported those findings. East Asians scored 4.6, whereas Westerners scored 3.8 on Darke and Freedman's (1993) Belief in Good Luck Scale $(\mathrm{F}(1,66)=10.92, p<.01)$.

Participants. Seventy patrons of two bookstores: Kepler's in Mountain View (CA, United States) and Flow in Central (HK, SARS) participated in the study (36\% females and $64 \%$ males, mean age $=32$ ). Patrons were screened to be either Caucasians born in the United States $(\mathrm{n}=39)$ or Chinese born in Asia $(\mathrm{n}=31)$.

Stimuli and Procedure. This study was conducted during the months of May and June both in Mountain View (CA) and Hong Kong (SARS). People were approached as 
they were leaving the bookstore and were asked whether they would participate in a short customer survey. Those who accepted were told that they would be given a gift as a token of appreciation (either a $\$ 5$ gift certificate or a branded coffee mug, both highly desirable although the $\$ 5$ certificate was preferred to the coffee mug: $M=6.3$ vs. $5.15 ; \mathrm{F}(1,69)=$ 26.66, $p<.01)$. Half of the participants entered the "Lucky Game" to win the gift. The other half simply received the unexpected gift without participating in a game. In the "Lucky Game", participants had to draw a ticket from a jar filled with tickets. Those who drew a winning number received the gift. Participants believed the chance of winning was $50 \%$, but in reality, all tickets had winning numbers.

After participants received their gift, they were asked "How pleased (excited, happy) are you currently feeling?" on a one to seven rating scale. At that point, participants evaluated the bookstore in terms of customer satisfaction: "Are you satisfied with your experience at Bookstore X?" on a one to seven rating scale (where $1=$ "Very Unsatisfied" and 7 = "Very Satisfied") and likelihood of future purchase: "How likely is it that you would buy your next book at Bookstore X?" on a 1 to 7 rating scale (where $1=$ "Very Unlikely" and 7 = "Very Likely"). Respondents also rated their feelings of surprise and hindsight as in prior studies. Finally, they were asked to report the cause(s) for the gift (Weiner 1985): Did they get the gift due to effort, ability, or luck? Instructions stated that they could check as many options as applied.

Momentary Pleasure. We expected that East Asians would derive greater pleasure than Westerners from an unexpected, lucky gift. We constructed the composite pleasure variable (alpha $=0.70)$ and found a significant interaction between luck (lucky game vs. 
no game) and culture on reported pleasure $\left(F(1,68)=9.66, p<.01, \eta^{2}=.12\right)$. This interaction is depicted in figure 4a. Reported pleasure increased significantly for East Asians when they received the unexpected gift attributed to luck $(M=4.82$ vs. $3.72 ; F(1$, $30)=4.06, p<.05, \eta^{2}=.12$ ). Westerners' reactions to the gift were, in fact, less positive when luck was introduced $\left(M=4.45\right.$ vs. $\left.5.68 ; F(1,38)=6.38, p<.01, \eta^{2}=.14\right)$. As predicted, East Asians derive greater pleasure from an unexpected positive event when it is attributed to luck than when it is not.

$$
\text { Insert figure } 4 \text { about here }
$$

Surprise and Hindsight. Figure $4 \mathrm{~b}$ shows experienced surprise plotted against expectations with separate curves for each culture. East Asians reported greater surprise when the unexpected gift was connected to the "Lucky Game" than when it was not ( $M=$ 5.00 vs. $\left.3.56 ; F(1,30)=5.44, p<.05, \eta^{2}=.07\right)$. Westerners reported slightly less surprise when the gift was connected to the "Lucky Game" than when it was not, although the difference was only marginally significant $(M=3.43$ vs. $4.49 ; F(1,38)=$ $\left.2.70, p<0.10, \eta^{2}=.05\right)$.

We performed the same moderated mediation analysis described in experiment 2. Results provide evidence for the predicted interaction between type of gift context (attributable to good luck or not) (X) and culture (Mo) on pleasure (see table 2). The effect of an unexpected gift on momentary pleasure was moderated by culture $\left(b_{13}=\right.$ .445). Second, there was a significant interaction between type of gift context $(\mathrm{X})$ and culture $(\mathrm{Mo})$ on experienced surprise $\left(\mathrm{b}_{23}=.491\right)$. There was also a significant effect of surprise on pleasure $\left(b_{34}=.365\right)$. Finally, the interaction between culture and type of gift 
context is smaller and only marginally significant after controlling for surprise $(|.272|<$ |.445|). We also calculated the Sobel's test of the mediation pattern, which results in a value of $2.01, p<.05$. Thus, experienced surprise mediates cultural differences on reported pleasure depending on whether the incentive gift is received through the "Lucky Game" or not.

Insert table 2 about here

Results for judged hindsight when the gift was unannounced resembled those in the previous experiments. Mean probability beliefs about a gift were lower (marginally) for Westerners than East Asians (12\% vs. $28 \%$, respectively; $F(1,30)=2.60, p<.10, \eta^{2}=$ .07). However, results changed when the gift was connected to the "Lucky Game." Westerners' probability beliefs increased from $12 \%$ to $37 \%\left(F(1,38)=7.06, p<.05, \eta^{2}\right.$ $=.10)$. We believe that the reason for the change in Westerners' probability beliefs is that instructions cued them that the probability of winning the game was $50 \%$, thus, beliefs were adjusted based on that cue. On the other hand, East Asians probability beliefs did not change significantly by condition $(28 \%$ and $38 \%$, respectively; $F(1,30)=1.60, p>$ $\left..15, \eta^{2}=.04\right)$. As a consequence, judged hindsight and experienced surprise were correlated for Westerners $(r=-0.31, p<.05)$ but not for East Asians $(r=0.17, p>.30)$. The greater momentary pleasure and surprise among East Asians when the unexpected gift is connected to the "Lucky Game" may be related to the type of attributions made about the intervening force behind the unexpected gift. 
Luck as the Intervening Force. When the unexpected gift was not connected to the "Lucky Game," both Westerners and East Asians attributed the gift to luck (53\% and $56 \%$, respectively) and effort (32\% and 33\% of the time, respectively). An additional $21 \%$ when the gift was not connected to the "Lucky Game" attributed the gift to difficulty. However, when the gift was connected to the "Lucky Game," the pattern of attributions changed such that while $52 \%$ of Westerners attributed it to effort, only $25 \%$ of East Asians did $\left(\chi^{2}(1)=3.28, p<.05, \eta^{2}=.28\right)$. On the other hand, while only $47 \%$ of Westerners attributed it to luck, $70 \%$ of East Asians $\operatorname{did}\left(\chi^{2}(1)=2.84, p<.08, \eta^{2}=\right.$ .22). Finally, 14\% of Westerners and 5\% of East Asians, respectively, attributed it to difficulty $\left(\chi^{2}(1)=1.03, p>.30, \eta^{2}=.15\right)$. In sum, East Asians were more likely than Westerners to attribute fate-signaling properties to an unexpected gift when the gift was part of the "Lucky Game."

In the case of East Asians, attributions of the incentive to luck may predict surprise judgments better than probability beliefs. We compare experienced surprise by whether the gift was attributed to luck or not. Consistent with our expectations, East Asians exhibited more surprise when the incentive was attributed to their personal luck than when it was not $\left(M=4.9\right.$ vs. 4.0 , respectively; $\left.F(1,30)=2.87, p<.07, \eta^{2}=.15\right)$.

Discussion. Experiment 4 shows that when East Asians encounter unexpected events, they experience greater pleasure if they can attribute those events to luck. We believe that East Asians further enjoy such changes because they signal harmony, connectedness, and positive things to come. For both Westerners and East Asians, emotional reactions to the incentive were mediated by the experience of surprise. For 
Westerners, surprise was correlated with probability beliefs. For Easterners, this relationship did not hold. Instead, judged surprise increased with attributions of the gift to their personal good fortune.

\section{GENERAL DISCUSSION}

In this article, we investigate whether East Asian and Western consumers experience different emotional reactions to an unanticipated incentive (a gift) and propose that both cognitive and motivational processes may underlie cross-cultural differences in regard to surprise and pleasure. Although cultural research tends to focus on either cognitive or motivational explanations, our research supports the notion that both processes may be at work. Westerners and East Asians tend to rely on different modes of thought (Choi and Nisbett 2000), which influence causal attributions and explanations of the unexpected. Moreover, Westerners and East Asians also differ in their desire to maintain the status quo. For Westerners, an unexpected gift may reinforce feelings of control over their current environments. For East Asians, an unexpected gift may indicate imbalance and prophesize bad fortune. Motivated toward balance, East Asians may reappraise past assumptions, taking the surprise out of the unexpected, indeed, in effect, removing the "un" from the "unexpected." These article's findings suggest that motivational processes prevail in explaining the cultural differences in consumer reactions to unexpected initiatives, but that they also trigger cognitive reappraisals of probability beliefs.

Experiment 1 supports that Westerners derive greater pleasure than East Asians from an unannounced incentive relative to two baselines-no incentive and an equivalent 
announced incentive. Experiment 2 replicates these results. Once again, culture moderates the effect expectations had on pleasure. Although in principle, the lower the expectation, the higher should be the surprise, expectations can be controlled by hindsight, which lowers the effect of surprise, and in turn, the effect surprise has on pleasure. Experiment 2's results show that Westerners exhibit less hindsight than East Asians when evaluating an unexpected incentive. Interestingly, East Asian's experience of surprise was correlated with their desire for personal control and confidence in their emotional balance. In sum, we find support for the idea that, for East Asians, the experience of surprise seemed to be closely connected to motivational processes.

If that is the case, to maximize an East Asian's pleasure from an unexpected incentive one could i) reduce the motivation to stay in control; or ii) enhance his enjoyment of a changing environment. Experiment 3's findings confirmed that East Asians, when primed to put less emphasis on emotional control, exhibit similar patterns of momentary pleasure, experienced surprise and hindsight after an unexpected incentive to those previously identified for Westerners.

Experiment 4 was a field experiment, which examined the idea that if East Asians perceive the intervening force behind an unexpected event to be their "good fortune," then, they may enjoy those events more than comparable unexpected events not attributable to luck. Luck is a positive sign from the universe. Since East Asians believe in destiny control, they may exhibit more positive feelings when they can attribute an unexpected incentive to intangible, fate-related influences, such as good luck. As a consequence, unexpected incentives connected to luck may create delight. Experiment 4's results support this notion. Emotional reactions are again mediated by the experienced 
surprise from the event. However, East Asians experience of surprise was correlated with the extent to which they attributed the incentive to luck instead of effort. It could even be argued that Westerners find games as a context to test their ability, whereas East Asians perceive them as a good-fate context by itself.

Our results add to past research that demonstrates the affective benefits of surprise. Wilson and colleagues (2005) find that the pleasure of a positive incentive (a gift of a gold coin) with an uncertain cause is prolonged relative to the same event with a certain cause. Norton and colleagues find similar effects in evaluations of interpersonal attraction in the context of on-line dating. In particular, less information about an upcoming date can often lead to greater liking (Norton, Frost and Ariely 2007). These benefits of surprise may differ across cultural identities and values. Cultural identity, in part, determines what is pleasurable and, thus, how to react to the unexpected. It shapes individually rooted needs and motives. Our findings support the idea that the culturally rooted affect system influences consumers' cognitive deliberations. These, in turn, shape the intensity of emotional reactions. For some cultures, there are benefits to surprising incentives, but for others, the benefit requires an association with luck.

More broadly, our results support the idea that affective and deliberative systems interact in decision making (for a recent view, see Loewenstein and O'Donoghue 2004). For example, the affective system can influence the deliberative system through "motivational biases" (Kunda 1990). An example of a motivational bias is cigarette craving, which not only directly motivates smoking but also the misjudgment of the costs and benefits of such behavior (Sayette et al. 2001). We find that the motivation for balance and control affects individuals' judgment of how unexpected an event is, which 
in turn shapes the affective response. Finally, our results are consistent with other recent studies, which suggest that individuals must reach some threshold of motivation to trigger cognitive processes that are consistent with their cultural beliefs (Briley and Aaker 2006).

Our findings have practical implications for international marketing strategies. Marketers often use pleasant surprises to influence consumers' brand evaluations and purchase decisions. In fact, the marketing literature emphasizes the role of consumer delight as a source of competitive advantage (Oliver et al. 1997). However, unexpected marketing activities must accommodate cross-cultural differences. Westerners are delighted with an unexpected gift offered as a token of appreciation for a prior action. East Asians are delighted with an unexpected gift offered as a lucky sign of good fortune. Promotional programs that include unexpected gifts and offerings should adopt either an effort-based or a luck-based format depending on the cultural orientation of the target consumer.

Naturally, our findings are limited in several ways. There may be cultural differences in our measurement tools (e.g., Steenkamp and Baumgartner 1998). East Asians have been shown to use the midpoint in rating scales more than North Americans; while U.S. participants have been shown to use more extreme values (Chen, Lee and Stevenson 1995). Therefore, the cross-cultural differences in self-reported affect could be due to differential response biases. Fortunately, we found similar responses across cultures in our baseline outcomes, and the identified pattern reversal in Experiment 4 rules out the idea that U.S. participants respond more extremely to affective events. Additionally, Chen et al. (1995) found that even when cultural biases in response styles are taken into account, comparisons between cultural groups do not usually change in a 
significant way. A third limitation is our sampling method since we only used convenience samples.

Nonetheless, the results are promising and account for a conservative test of cross-cultural differences in consumer responses to unexpected incentives. Future research will undoubtedly find other cross-cultural differences. Indeed the tension between cognitive and motivational mechanisms, as well as the potential for contribution, is greater in the cross-cultural research field than in other fields. Additional research should more clearly establish the circumstances or domains under which motivational explanations dominate cognitive explanations of cultural phenomena. There is still much to learn about international sensitivities, and the more we can discover about them, the better global marketing strategies will be. 


\section{References}

Anonymous (1996), “Have You Ever Used a "Surprise” Incentive?” The American Salesman, 41(2), 26.

Berman, Barry (2005), "How to Delight Your Customers," California Management Review, 48(1), 129-151.

Briley, Donnel A. and Jennifer L. Aaker (2006), "When Does Culture Matter? Effects of Personal Knowledge on the Correction of Culture-Based Judgments," Journal of Marketing Research, 43(3), 395-408.

Burger, Jerry M. and Harris M. Cooper (1979), "The Desirability of Control," Motivation and Emotion, 3(4), 381-393.

Butler, Emily, Lee, Tiane and James Gross (2007), "Emotion Regulation and Culture: Are There Social Consequences of Emotion Suppression Culture-Specific?” Emotion, 7(1), 30-48.

Chen, Chuansheng, Shin-ying Lee, and Harold W. Stevenson (1995), "Response Style and Cross-Cultural Comparisons of Rating Scales Among East Asians and North American Students," Psychological Science, 6(3), 170-175.

Chiu, Lian-Hwang (1971), "Manifested Anxiety in Chinese and American Children," The Journal of Psychology, 79(2), 273-284.

Choi, Incheol, Richard E. Nisbett, and Ara Norenzayan (1999), "Causal Attribution across Cultures: Variation and Universality," Psychological Bulletin, 125, 47-63.

Choi, Incheol, and Richard E. Nisbett (2000), "Cultural Psychology of Surprise: Holistic Theories and Recognition of Contradiction," Journal of Personality and Social Psychology, 79(6), 890-905. 
Choi, Incheol, Minkyung Koo and Jong An Choi (2007), "Individual Differences in Analytic versus Holistic Thinking," Personality and Social Psychology Bulletin, 33, 691-705.

Darke Peter R. and Jonathan L. Freedman (1997), “The Belief in Good Luck Scale,” Journal of Research in Personality, 31(4), 486-511.

Diener Ed and Eunkook Mark Suh (2003), "National Differences in Subjective Well-Being," in Well-being: The Foundations of Hedonic Psychology, eds. Daniel Kahneman, Edward Diener, and Norbert Schwarz, Russell Sage Foundation: NY, 434-452.

Ekman, Paul, Wallace V. Friesen, and Phoebe Ellsworth (1972), Emotion in the Human Face: Guidelines for Research and an Integration of Findings. New York: Lawrence Erlbaum. Elster, Jon (1998), “Emotions and Economic Theory,” Journal of Economic Literature, 36 (2), $47-74$.

Filipowicz, Allan (2006), "From Positive Affect to Creativity: The Surprising Role of Surprise," Creativity Research Journal, 18(2), 141-152.

Fischhoff, Baruch (1975), "Hindsight $\neq$ Foresight: The Effect of Outcome Knowledge on Judgment under Uncertainty," Journal of Experimental Psychology: Human Perception and Performance, 104, 288-299.

Fiske, John E. (2002), “Judgments under Uncertainty: Representativeness or Potential Surprise?" British Journal of Psychology, 93 (4), 431-449.

Fiske, Alan Page, Shinobu Kitayama, Hazel Rose Markus, and Richard E. Nisbett (1998), "The Cultural Matrix of Social Psychology," in The handbook of social psychology, eds., D.T. Glibert, S.T. Fiske, and G. Lindzery, Boston: McGraw-Hill, 915-981. 
Gross, James J. and Oliver P. John, (2003), “Individual Differences in Two Emotion Regulation Processes: Implications for Affect, Relationships, and Well-being," Journal of Personality and Social Psychology, 85(2), 348-362.

Heilman, Carrie M., Kent Nakamoto, and Ambar G. Rao (2002), "Pleasant Surprises: Consumer Response to Unexpected In-store Coupons," Journal of Marketing Research, 39(2), 242252.

Heider, Fritz (1958), The Psychology of Interpersonal Relations, New York: Wiley.

Heine, Steven J. and Darrin R. Lehman (1997), "Culture, Dissonance, and Self-affirmation," Personality and Social Psychology Bulletin, 23(April), 389-400.

Heine, Steve H., Darrin R. Lehman., Hazel R. Markus, and Shinobu Kitayama (1999), "Is There a Universal Need for Positive Self-regard," Psychological Review, 106. 766-794.

Kahneman, Daniel and Dale T. Miller (1986), "Norm Theory: Comparing Reality with Its Alternatives," Psychological Review, 93 (2), 136-153.

Kim, Bryan S. K., Donald R. Atkinson, and Peggy H. Yang (1999), “The Asian Values Scale: Development, Factor Analysis, Validation, and Reliability," Journal of Counseling Psychology, 46(3), 342-352.

Kitayama, Shinobu and Hazel Rose Markus (2000), "The Pursuit of Happiness and the Realization of Sympathy: Cultural Patterns of Self, Social Relations, and Well-being," in Culture and subjective well-being, eds. E. Diener and E. M. Sub, Cambridge, MA: MIT Press, 113-161.

Kunda, Ziva (1990), “The Case for Motivated Reasoning,” Psychological Bulletin, 108, 480-498. Langer, E. J. (1975), “The Illusion of Control,” Journal of Personality and Social Psychology, 32, 311-328. 
Larsen, Randy J., Ed Diener, and Robert A. Emmons (1985), “An Evaluation of Subjective Wellbeing Measures," Social Indicators Research, 17, 1-17.

Lee, Yih H. (2000), "Manipulating Ad Message Involvement through Information Expectancy: Effects on Attitude Evaluation and Confidence," Journal of Advertising, 29, 29-44.

Li, Chenyang (2006), "The Confucian Ideal of Harmony," Philosophy East and West, 56(4), 583-603.

Loewenstein, George and Ted O’Donoghue (2004), “Animal Spirits: Affective and Deliberative Processes in Economic Behavior,” Working paper, University of Carnegie-Mellon.

Markus, Hazel Rose and Shinobu Kitayama (1991b), "Cultural Variation in Self-concept: Implications for Cognition, Emotion, and Motivation," Psychological Review, 98, 224-253.

Markus, Hazel Rose and Shinobu Kitayama (1994), “A Collective Fear of the Collective: Implications for Selves and Theories of Selves," Personality and Social Psychology Bulletin, 20(5), 568-579.

Mellers, Barbara A., Alan Schwartz, and Ilana Ritov (1999), “Emotion-Based Choice,” Journal of Experimental Psychology: General, 128 (3), 1-14.

Mellers, Barbara A., Alan Schwartz, Katty Ho, and Ilana Ritov (1997), "Decision Affect Theory: Emotional Reactions to the Outcomes of Risky Options," Psychological Science, 8 (6), 423-429.

Mellers, Barbara A., and Peter A. McGraw (2001), “Anticipated Emotions as Guides to Choice," Current Directions, 10(6), 210-214.

Muller, Dominique, Charles Judd, and Vincent Y. Yzerbyt (2005), "When Moderation is Mediated and Mediation is Moderated," Journal of Personality and Social Psychology, 89(6), 852-863. 
Nisbett, Richard E., Kaiping Peng, Incheol Choi, and Ara Norenzayan (2001), "Culture and Systems of Thought: Holistic vs. Analytic Cognition," Psychological Review, 108, 291310.

Norenzayan, Ara, Incheol Choi, and Richard E. Nisbett (1999), "Eastern and Western Perceptions of Causality for Social Behavior: Lay Theories About Personalities and Social Situations," in Cultural divides: Understanding and Overcoming Group Conflict, eds. D. Prentice and D. Miller, New York: Sage, 239-272.

Norton, Michael I., Frost, Jeana H., and Ariely, Dan (2007), “Less Is More: The Lure of Ambiguity, or Why Familiarity Breeds Contempt," Journal of Personality and Social Psychology, 92(1), 97-105.

Oliver, Richard L., Roland T. Rust, and Sajeev Varki (1997), “Customer Delight: Foundations, Findings and Managerial Insight,” Journal of Retailing, 73(3), 311-336.

Peng, Kaiping and Richard E. Nisbett (1999), "Culture, Dialectics and Reasoning about Contradiction," American Psychologists, 54, 741-754.

Sayette, M. A., Martin, C. S., Wertz, J. M., Shiffman, S., and Perrott, M. A. (2001), “A Multidimensional Analysis of Cue-elicited Craving in Heavy Smokers and Tobacco Chippers," Addiction, 96, 1419-1432.

Schultz, Wolfram and Peter Dayan (1997), "A Neural Substrate of Prediction and Reward," Science, 275 (5306), 1593-1600.

Steenkamp, Jan-Benedict E.M., and Hans Baumgartner (1998), “Assessing Measurement Invariance in Cross-National," Consumer Research, 25 (June), 78-90.

Suh, Eunkook, M. (2002), “Culture, Identity Consistency, and Subjective Well-being,” Journal of Personality and Social Psychology, 83, 1378-1391. 
Teigen, Karl H. and Gideon Keren (2003), “Surprises: Low Probabilities or High Contrast?" Cognition, 87 (2), 55-71.

Uchida, Yukiko, Vinai Norasakkunkit and Shinobu Kitayama (2004) "Cultural Constructions of Happiness: Theory and Empirical Evidence,” Journal of Happiness Studies, 5, 223-239

Uno, T (1991), Chinese ideology, Seoul, South Korea: Daewon.

Weiner, B. (1985), “An Attributional Theory of Achievement Motivation and Emotion,” Psychological Review, 92, 548-573.

Weisz, John R., Fred M. Rothbaum, and Thomas Blackburn (1984), “Standing Out and Standing in: The Psychology of Control in America and Japan," American Psychologist, 39(9), 955-969.

Wilson, Timothy D., Centerbar, David B., Kermer, Deborah A., and Daniel T. Gilbert (2005), "The Pleasures of Uncertainty: Prolonging Positive Moods in Ways People Do Not Anticipate," Journal of Personality and Social Psychology, 88(1), 5-21.

Williams, Patti W., and Jennifer L. Aaker (2002), “Can Mixed Emotions Peacefully Coexist?” Journal of Consumer Research, 28 (March), 636-649.

Yang-Soo, Rhee (1981), “A Cross-cultural Comparison of Korean and American Managerial Styles," Global Economic Review, 10(2), 45-63.

Young, Maia J., Michael W. Morris, Lilavati Krishnan, and Murari Prasad Regmi (2005), "Forms of Fatalism: Christian and Hindu Approaches to Attributing Misfortune and Coping with Risks," Working paper UCLA Anderson School. 
Table 1

Experiment 2: Least Square Regression Results for Mediated Moderation of Pleasure by Surprise

\begin{tabular}{|c|c|c|c|c|c|c|}
\hline \multirow[b]{2}{*}{ Predictors } & \multicolumn{2}{|c|}{$\begin{array}{l}\text { Equation } 1 \\
\text { (criterion } \\
\text { Pleasure) }\end{array}$} & \multicolumn{2}{|c|}{$\begin{array}{c}\text { Equation } 2 \\
\text { (criterion } \\
\text { Surprise) }\end{array}$} & \multicolumn{2}{|c|}{$\begin{array}{c}\text { Equation } 3 \\
\text { (criterion } \\
\text { Pleasure) }\end{array}$} \\
\hline & $b$ & $t$ & $b$ & $t$ & $b$ & $t$ \\
\hline $\begin{array}{l}\text { X: Beliefs about } \\
\text { incentive's } \\
\text { occurrence } \\
\text { (-1 = expected, } 1= \\
\text { unexpected) }\end{array}$ & .193 & $1.925^{2}$ & .511 & $3.720^{1}$ & -.040 & -.490 \\
\hline $\begin{array}{l}\text { MO: Cultural } \\
\text { orientation } \\
(-1=\text { Western, } 1=\text { East } \\
\text { Asian) }\end{array}$ & -.068 & -.682 & -.056 & -.406 & -.074 & -.325 \\
\hline $\begin{array}{l}\text { XMO: Interaction } \\
\text { Beliefs* Culture }\end{array}$ & -.202 & $-2.017^{1}$ & -.340 & $-2.476^{1}$ & -.049 & -.599 \\
\hline $\begin{array}{l}\text { ME: Experienced } \\
\text { surprise }\end{array}$ & & & & & .461 & $9.539^{1}$ \\
\hline $\begin{array}{l}\text { MEMO: Interaction } \\
\text { Surprise * Culture }\end{array}$ & & & & & .007 & .145 \\
\hline
\end{tabular}

According to Muller, Judd and Yzerbyt (2005), a mediated moderation analysis requires three regressions:

The first regression predicts reported pleasure $(\mathrm{Y})$ based on beliefs about the incentive's occurrence $(\mathrm{X})$, culture (Mo), and the interaction between gift announcement and culture (XMo), as follows:

$$
\mathrm{Y}=\mathrm{b}_{10}+\mathrm{b}_{11} \mathrm{X}+\mathrm{b}_{12} \mathrm{Mo}+\mathrm{b}_{13} \mathrm{XMo},
$$

where $b_{0}, b_{11}, b_{12}$, and $b_{13}$ refer to least squares regression weights, respectively, in Eq 1 . The second regression predicts the mediator, judged surprise $(\mathrm{Me})$, from the same three variables:

$$
\mathrm{Me}=\mathrm{b}_{20}+\mathrm{b}_{21} \mathrm{X}+\mathrm{b}_{22} \mathrm{Mo}+\mathrm{b}_{23} \mathrm{XMo} .
$$

The third regression predicts reported pleasure $(\mathrm{Y})$ from the three previous variables, plus judged surprise $(\mathrm{Me})$, and the interaction between judged surprise and culture (MeMo):

$$
\mathrm{Y}=\mathrm{b}_{30}+\mathrm{b}_{31} \mathrm{X}+\mathrm{b}_{32} \mathrm{Mo}+\mathrm{b}_{33} \mathrm{XMo}+\mathrm{b}_{34} \mathrm{Me}+\mathrm{b}_{35} \mathrm{MeMo} .
$$

Assumptions: $\mathrm{X}$ has two levels with random assignment to each level, $\mathrm{X}$ and Mo are uncorrelated, and Me and Mo are zero-centered. 
Table 2

Experiment 4: Least Square Regression Results for Mediated Moderation of Pleasure by Surprise

\begin{tabular}{|c|c|c|c|c|c|c|}
\hline & \multicolumn{2}{|c|}{$\begin{array}{c}\text { Equation } 1 \\
\text { (criterion } \\
\text { Pleasure) }\end{array}$} & \multicolumn{2}{|c|}{$\begin{array}{c}\text { Equation } 2 \\
\text { (criterion } \\
\text { Surprise) }\end{array}$} & \multicolumn{2}{|c|}{$\begin{array}{c}\text { Equation } 3 \\
\text { (criterion } \\
\text { Pleasure) }\end{array}$} \\
\hline Predictors & $b$ & $t$ & $b$ & $t$ & $b$ & $t$ \\
\hline $\begin{array}{l}\text { X: Incentive } \\
\text { connected to "Lucky } \\
\text { Game" or not } \\
(-1=\text { Not }, 1=\text { Lucky })\end{array}$ & -.164 & -1.106 & -.038 & -.179 & -.226 & $-1.671^{2}$ \\
\hline $\begin{array}{l}\text { MO: Cultural } \\
\text { orientation } \\
(-1=\text { Western, } 1=\text { East } \\
\text { Asian) }\end{array}$ & -.259 & $-1.749^{2}$ & .295 & 1.373 & -1.032 & $-3.145^{1}$ \\
\hline $\begin{array}{l}\text { XMO: "Lucky game" } \\
\text { * Culture }\end{array}$ & .445 & $3.007^{1}$ & .491 & $2.286^{1}$ & .272 & $2.009^{1}$ \\
\hline $\begin{array}{l}\text { ME: Experienced } \\
\text { surprise }\end{array}$ & & & & & .365 & $5.323^{1}$ \\
\hline $\begin{array}{l}\text { MEMO: Interaction } \\
\text { Surprise * Culture }\end{array}$ & & & & & .157 & $2.285^{1}$ \\
\hline
\end{tabular}

${ }_{2} \mathrm{t}$-statistic is significant at $p<.05$.

$2 \mathrm{t}$-statistic is significant at $p<.10$. 
Figure 1

a. MODERATING EFFECT OF CULTURAL ORIENTATION IN MOMENTARY PLEASURE FROM AN UNEXPECTED INCENTIVE

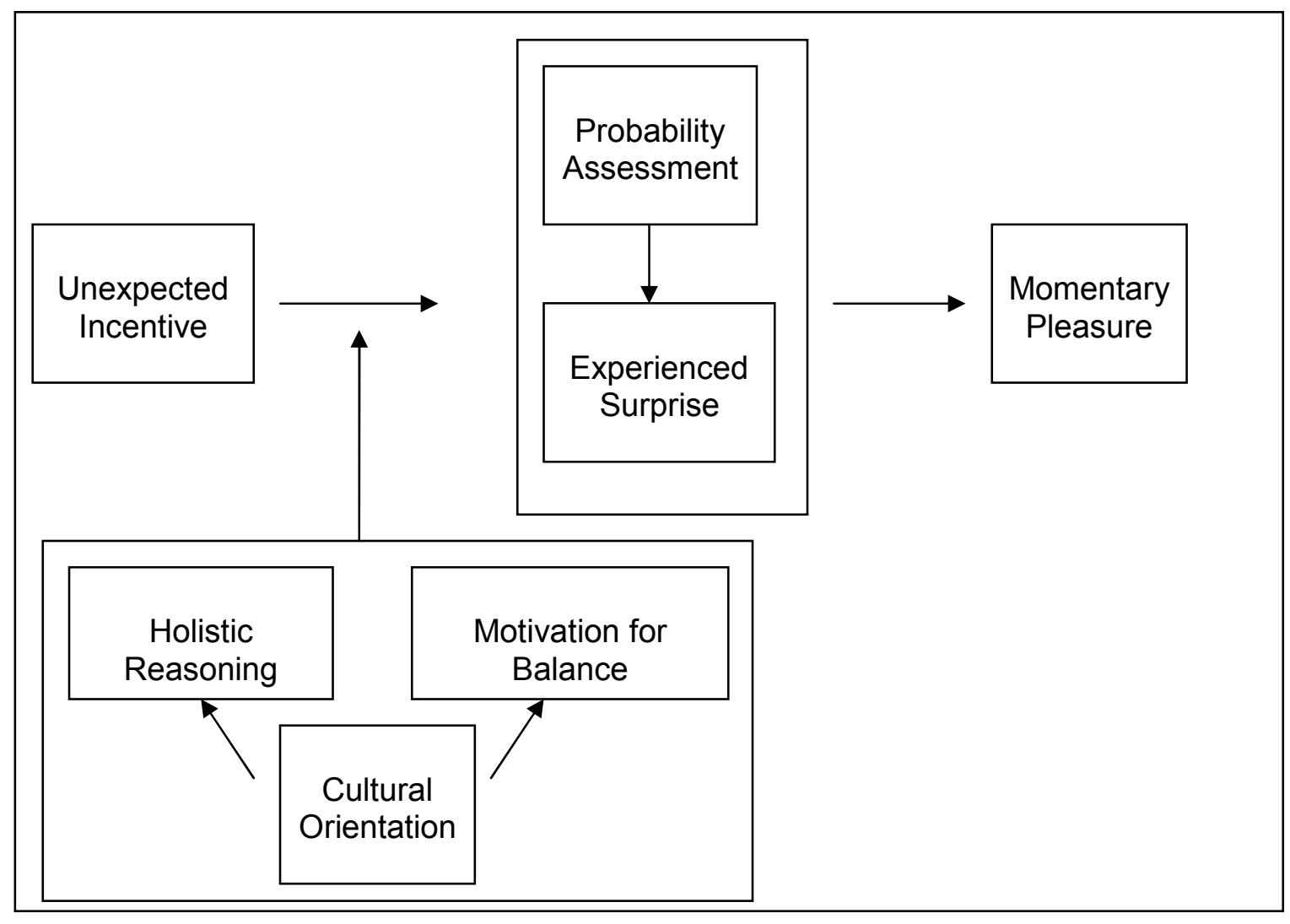

b. MODERATING EFFECT OF LUCK-BASED ATTRIBUTIONS IN MOMENTARY PLEASURE FROM AN UNEXPECTED INCENTIVE

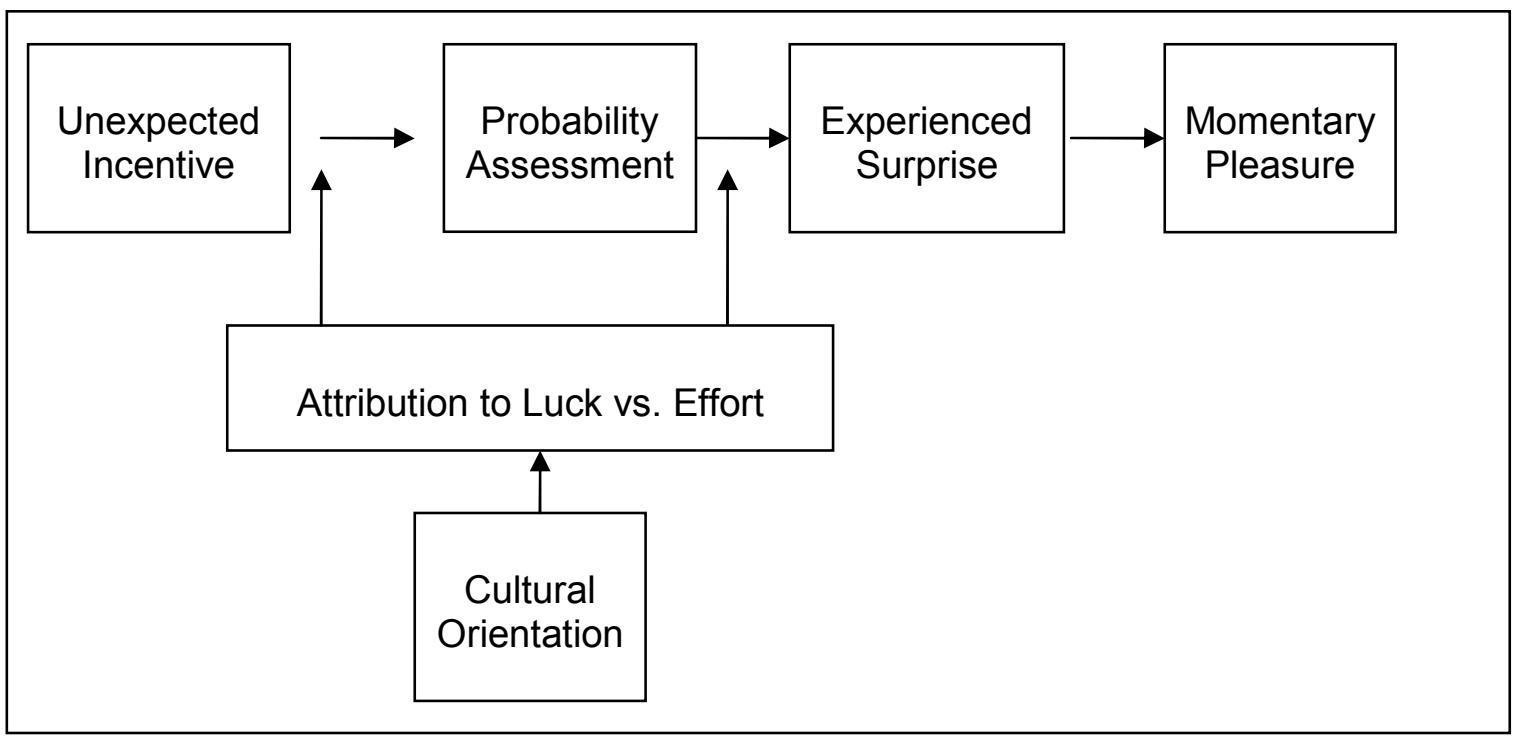


Figure 2

EXPERIMENT 1 RESULTS

Effects of Incentive Announcement and Culture on Reported Pleasure (West and East refer to Westerners and East Asians, respectively)

a. No gift versus unexpected gift.

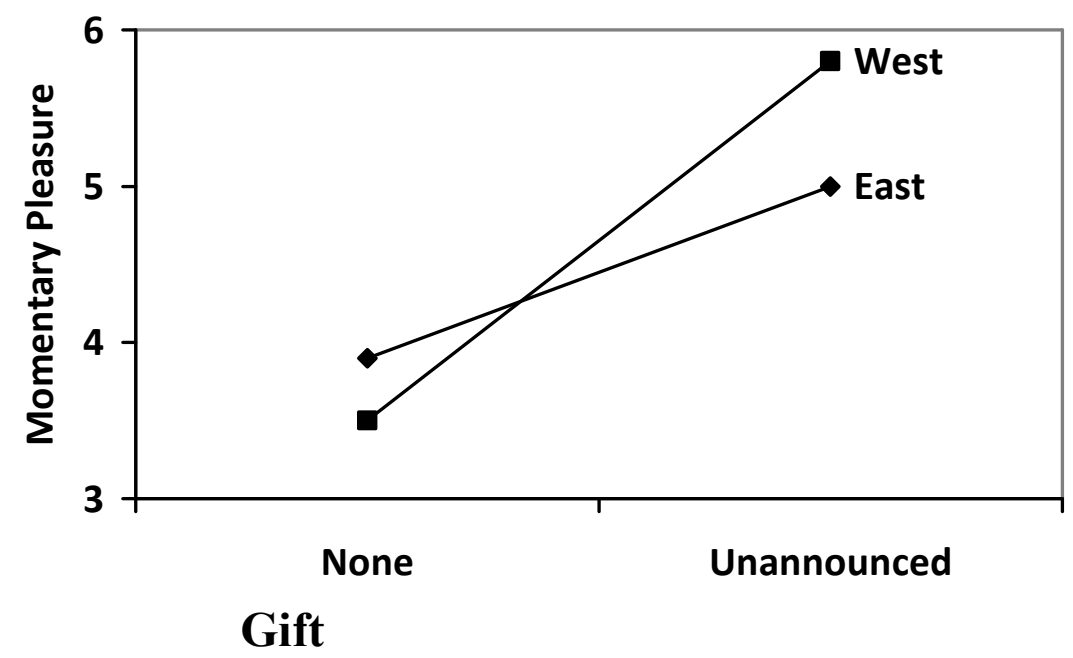

t.

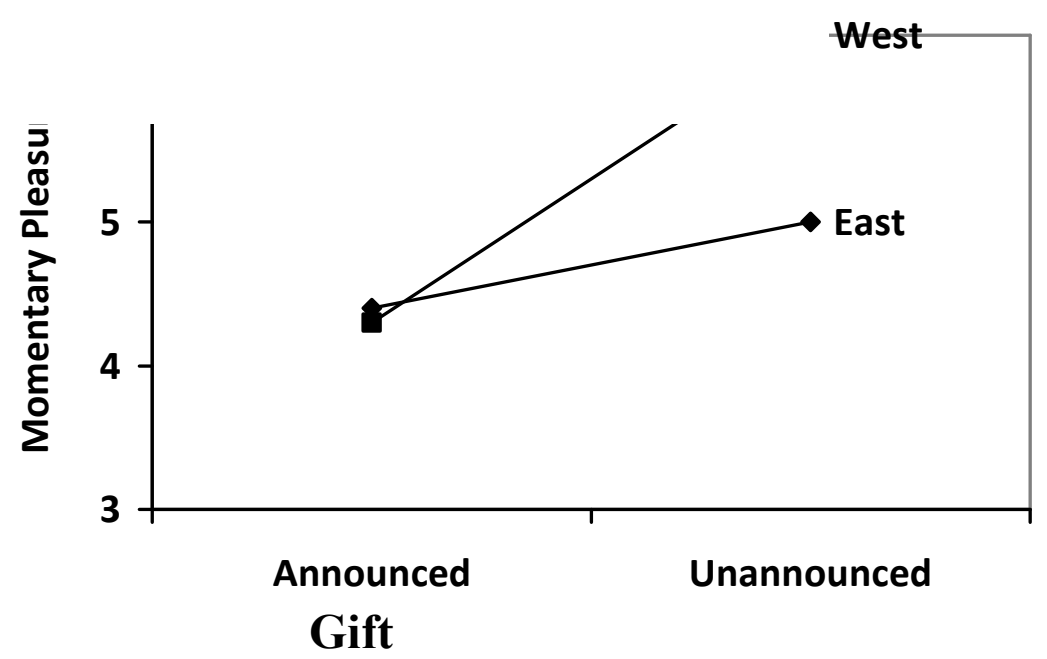


Figure 3

EXPERIMENT 2 RESULTS

a. Effects of incentive announcement and culture on reported pleasure.

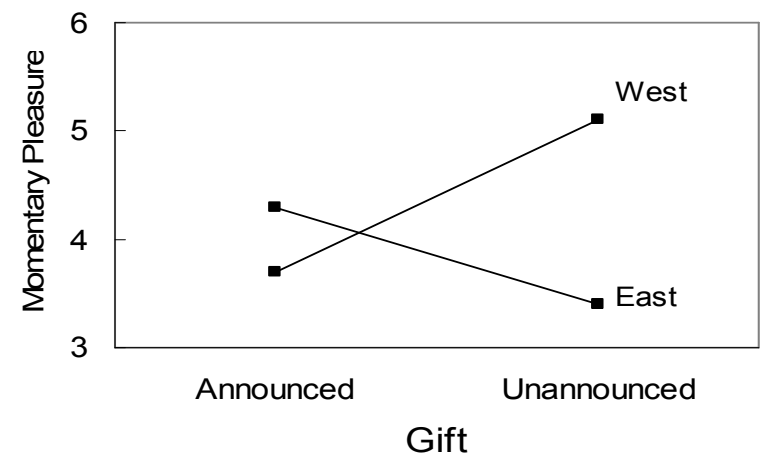

b. Effects of incentive announcement and culture on judged surprise.

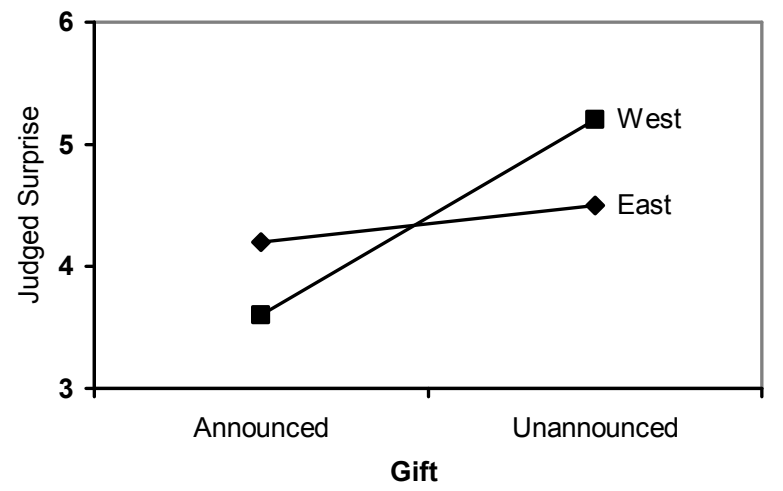

c. Effects of incentive announcement and culture on judged hindsight.

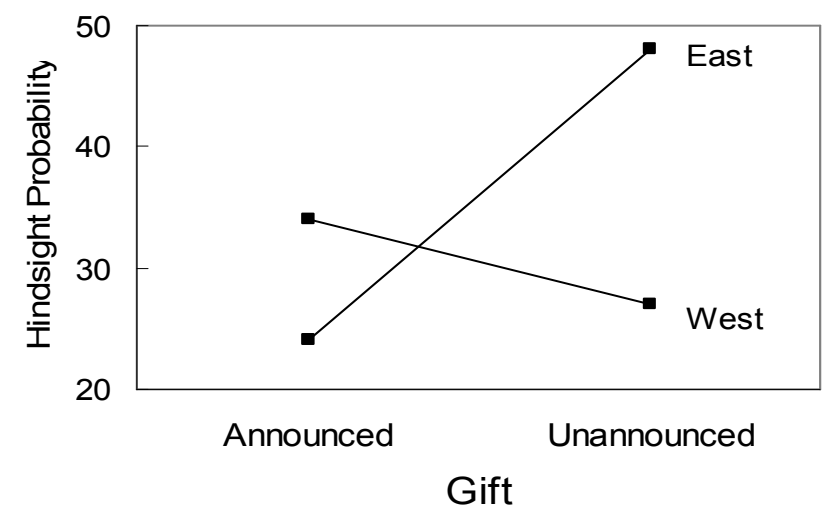


Figure 4

EXPERIMENT 4 RESULTS

a. Effects of incentive announcement, luck (lucky game vs. no game) and culture on reported pleasure.

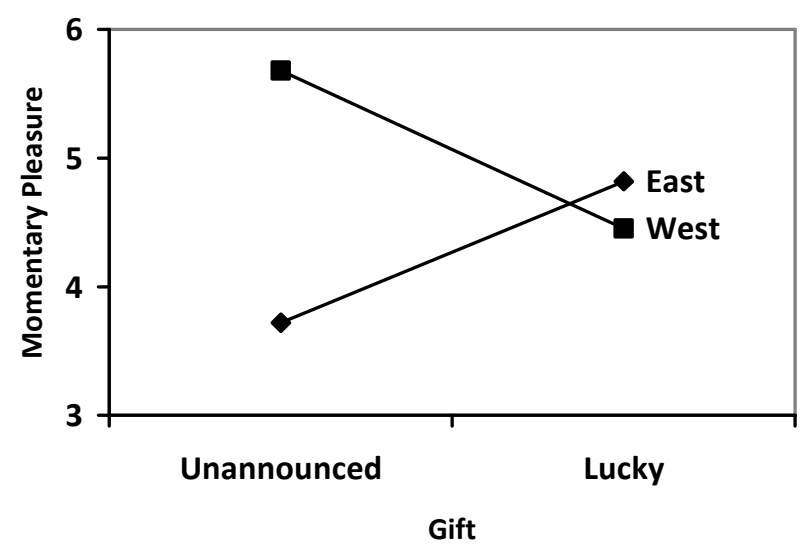

b. Effects of incentive announcement, luck (lucky game vs. no game) and culture on judged surprise.

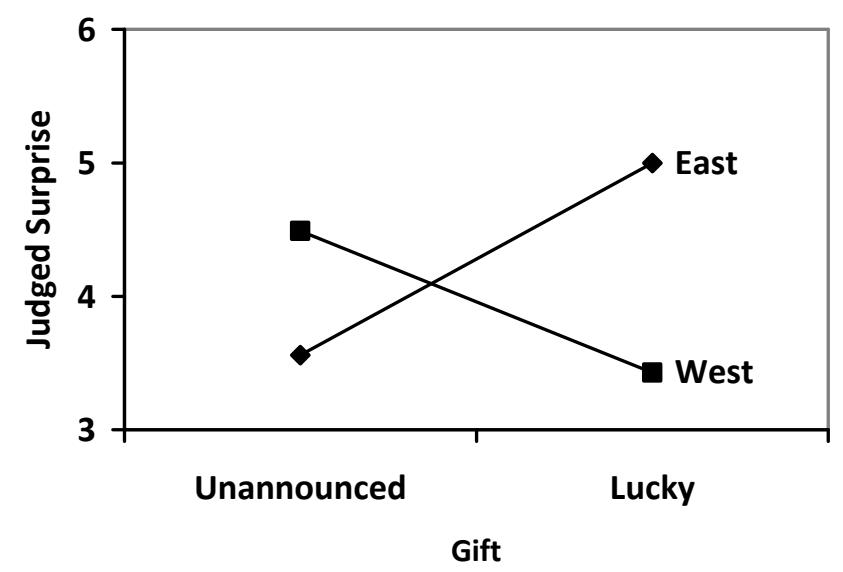

